\title{
Needle Shape Morphology of Natural Zeolites of Nazert,(Ethiopia)
}

\author{
MUKUL CHAUHAN \\ Department of Chemistry, HNB Garhwal University, Srinagar, Garhwal, India \\ mukul72_cn@yahoo.co.in
}

Received 9 April 2014 / Accepted 2 May 2014

\begin{abstract}
A brief report about geological history of Zeolites present in different localities of Ethiopia is presented. Scanning electron microscopy (SEM) was used to study the habit and surface topography of the samples collected in the rift valley region, Nazert (Ethiopia). Data collected from this studies carried out on the samples is presented. SEM micrographs of needle shape and elongated rod-like crystals are illustrated. Through chemical analysis, the samples are identified as Gismondine. A possible mechanism of growth and formation of various shapes of these natural Zeolites is proposed. Important industrial and agriculture applications of Zeolites are given. Future scope in this field is also explored.
\end{abstract}

Keywords: Zeolites, Molecular Sieves, Crystallization, Quartz

\section{Introduction}

Zeolites are crystalline, hydrated aluminosilicates of elements of group IA and IIA, particularly sodium, potassium, magnesium, calcium, strontium and barium. Structurally, the Zeolites are framework of aluminosilicates which are based on an infinitely extending threedimensional net work of $\mathrm{AlO}_{4}$ or $\mathrm{SiO}_{4}$ tetrahedral linked to each other by sharing of all the oxygen ${ }^{1}$.

Some unique Zeolites frame works have been identified and about 40 naturally occurring Zeolites frame works are known. These 40 species of Zeolite minerals are occurring in reasonably high quantities and purity ${ }^{2}$.

Zeolite minerals occur well developed single crystals as large as several millimeters. In some cases they are found as dense polycrystalline aggregates. Synthetic Zeolites are produced as crystalline powders with a typical particle size ranging from 1 to 140 microns $^{3}$. Electron microscopy is used extensively to study the habit and surface topography of synthetic Zeolites ${ }^{1}$.

Zeolites have high cation exchange capacities and specifically high ammonium selectivi ties $^{4}$.They are widely used in industry for water purification, as catalysts, for the preparation of 
advanced materials and in nuclear reprocessing. There are many applications of Zeolites in agriculture and horticultures ${ }^{5,6}$. In chicken houses zeolites reduce the losses of ammoniumnitrogen by its ion exchange and adsorption capacity. They are used to extract nitrogen from air to increase oxygen content for both industrial and medical purposes. Their biggest use is in the production of laundry detergents.

According to British Geological Survey and International Program-Commission report that Zeolites are present in the vicinity of Lake Tanna (The largest lake in Ethiopia) ${ }^{7}$. Extensive deposits of high grade Zeolite (Mordenite and Clinoptilolite) were discovered about more than a decade ago by geologists of the Ethiopia-Canada agro geology project in rift valley sediments near Nazret and Bora, west of Nazret. However, no follow up work appears to have been carried out so far on Zeolites. In view of wide industrial applications of Zeolites, in-depth studies related to their various properties by methods of investigations like Infra-red spectroscopy, $\mathrm{x}$-ray structural analysis and nuclear magnetic resonance etc. are being taken up, a detailed report about which shall be published elsewhere. A brief report about our preliminary investigations on the Zeolites of Ethiopia is given here

\section{Experimental}

Identification of the samples was carried out by usual chemical quantitative analysis procedures at the National Physical Laboratory, New Delhi, India by their standard HF fusion method of Aluminosilicate minerals ${ }^{8}$. Different chemical reagents were used to analyze different elements of the Zeolite samples. However, examination of habit and the surface topography of the samples were carried out by Scanning Electron microscope model ESEM EDAX XL-30 (MAKE Philips, Netherland) at the Sophisticated Instrumentation centre for Applied Research \& Testing, V.V. Nagar, India.

\section{Results and Discussion}

The results of chemical analysis of the specimen collected from Rift valley region, Nazert, Ethiopia are shown in the Table 1.

Table 1. Chemical composition of the sample

\begin{tabular}{lllllll}
\hline Content $\rightarrow$ & $\mathrm{Ca}$ & $\mathrm{Na}$ & $\mathrm{Al}$ & $\mathrm{H}$ & $\mathrm{Si}$ & $\mathrm{O}$ \\
\hline Percentage $\rightarrow$ & 8.55 & 0.91 & 15.92 & 2.50 & 16.01 & 56.11 \\
\hline
\end{tabular}

The percentage composition of the sample shows that the samples contained $\mathrm{Ca}, \mathrm{Al}$ and $\mathrm{Si}$ in majority and lesser quantity of $\mathrm{Ca}$ and very little $\mathrm{Na}$ are present. Further sample analysis indicates that almost equal proportions of $\mathrm{Al}$ and $\mathrm{Si}$ are present. These results point out that the Zeolite sample is Gismondine $\left(\mathrm{Ca} \mathrm{Al}_{2} \mathrm{Si}_{2} \mathrm{O}_{8}\right) 4 \mathrm{H}_{2} \mathrm{O}$ type mineral. One could perhaps think of it possibly as Anorthite, however, chances for that seem to be less as the shape of the samples does not match with the standard shape of Anorthite. The crystals of Gismondine up to $0.5 \mathrm{~cm}$ across were observed as isolated or intertwined on volcanic rock. The associated mineral Quartz occurred in the form of very tiny crystallites.

Electron microscopy was used to study the habit and surface topography of Zeolite samples. Figure 1 illustrates SEM micrograph of randomly oriented Gismondine crystals some with well developed faces and others appearing as irregular twinned aggregates. Rodlike longated and strictly oriented crystals with their longer sides parallel to C-axis are shown in the SEM micrograph (Figure 2). 


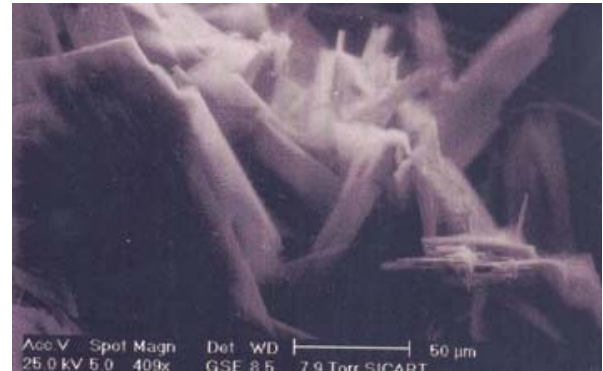

Figure 1. SEM micrograph showing randomly oriented Gismondine Zeolite crystals $\mathrm{x} 1000$

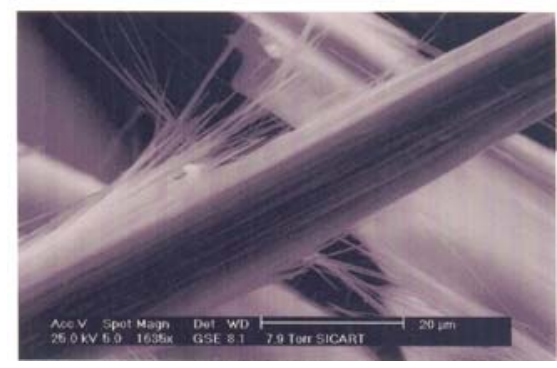

Figure 2. SEM micrograph of elongated rod-like and needle-shaped Zeolite crystals X1000

All these crystals have their size larger than 100 micron and have well developed faces. Growth of small needle-like whiskers is also seen sprouting out on the sides of the host crystals. In some cases spheroids of Zeolites were also observed (Figure 3). Here, the needles are radiating outwards from a central point.

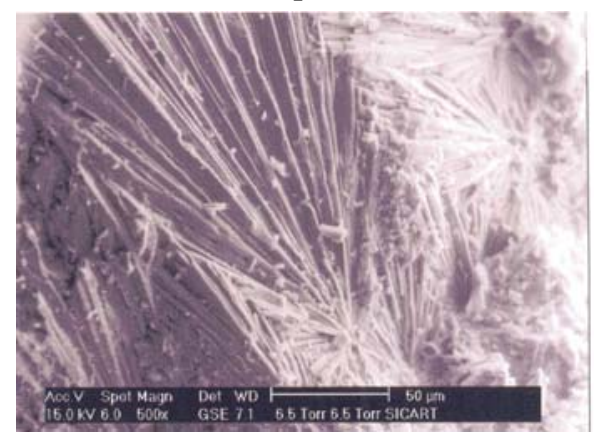

Figure 3. SEM micrograph of spheriod shape Zeolites with radiating out needles x1000

Mechanism of formation of elongated rod like crystals can occur by two dimensional nucleation process by spreading and piling up of growth layers. It is suggested that if rate of growth is faster along $\mathrm{C}$-axis and a large number of growth nuclei remain active along $\mathrm{C}$-axis as compared to those perpendicular to C-axis, elongated crystals can result. Relation among different forms of crystals in relation to growth rates has been explained by Sunagawa ${ }^{9}$. Habit exhibited by different crystals is simply due to growth along stronger bond direction. Habits like prismatic, tabular, lamellar and etc. species generally exhibit is due to anisotropy involved in bonding in the crystal structure. According to earlier research workers $^{4-6}$ natural Zeolites are unstable in the beginning and due to change in environmental conditions, change to a stable phase. According to Strickland-constable ${ }^{10}$ and Takoo ${ }^{11}$ when super saturation exceeds a certain limit, the result is an abnormal growth in the form of needles, rods and platelets. Controlling various crystallization parameters such as evaporation rates, degree of super saturation, deliberate addition of impurity, affects habit modification. It is reasonable to believe that the environmental conditions do change in nature and various shapes of morphologies as reported here leads one to conclude that variation in such growth morphologies is a function of super saturation value and fast evaporation rates as controlled by temperature in the environment. The nano -sized needlelike crystals with high crystal aspect ratio (length-to-width ratio) have better catalytic properties $^{12}$. 
Rod-like and needle-like Mordenite Zeolites show excellent mesepore property and thermal stability and same should possibly hold true for the needle like and rod-like morphologies of Zeolites reported here and therefore promises potential applications in adsorption and mild catalytic reactions ${ }^{13}$.

\section{Conclusion}

(a) The presence of Gismondine in the form of needles and/or rod-like shape crystals reported here is an important addition to the list of Zeolite deposits (Mordenite \& Clinoptilite) already discovered by geologists of the Ethiopian-Canada agro-geology project in the rift valley sediments near Nazret.

(b) The needle-like and rod-like morphologies of Gismondine zeolites should find wide applications in adsorption and catalytic reactions.

(c) These Zeolites could be utilized as base materials for the growth and development of new Zeolites with better catalytic properties by optimization of synthesis parameters.

(d) The subject offers wide scope as some of the urgent environmental problems may be solved in the next decade by using known properties of known Zeolites and closely related materials or perhaps by preparing a new Zeolite with desired chemical or physical properties required for agriculture and water purification purposes.

\section{Acknowledgement}

The authors wish to thank Professor J.G. Loius, Geological and Environmental Science Department, Stanford University, California USA for his helpful suggestion.

\section{References}

1. Breck D W, Zeolite Molecular Sieves: Structure, Chemistry and use, John Wiley, New York, 1974, 313.

2. Juan Manuel Triana R, Javier Francisco Herrera R, Carlos Alberto Ríos R. Oscar Mauricio Castellanos A, José Antonio Henao M, Craig D Williams and Clive L Roberts, Earth Sci Res J., 2012, 16(1), 41-53.

3. Szoztak R, Molecular Sieves, Blackie Academic and Professional, London, 1998, 359.

4. Mumpton F A, Use of natural zeolites in agriculture and aquaculture, Westview Press Boulder, Colorado, 1984, 247-254.

5. Allen E R and Ming D W, Recent progress in the use of natural zeolites in agronomy and horticulture, International Committee on Natural Zeolites, Brockport, New York, USA, 1995, 477-490.

6. Van Straaten $\mathrm{P}$ and Zeolites S, agriculture and horticulture, reduction of nitrogen losses, Abstract, Symposium of Geol Ass Canada: Industrial minerals in environmental applications Vancouver, Canada, Nov 18/19 ${ }^{\text {th }}, 1993$.

7. Morgan D J, Demand supply survey of the Ethiopian industrial minerals subsector, British geological survey commissioned report, CR/06/180, 2007, 12.

8. Paul Gaines, Elemental analysis of Zeolites, Inorganic Ventures Europe S L; http://www.inorganicventures.com/elemental-analysis-zeolites

9. Sunagawa L, $N$ Fortschr Miner., 1975, 52, 515.

10. Strickland-Constable R F, Kinetics and mechanism of crystallization from the fluid phase and of the condensation and evaporation of liquids, Published by Academic P., London New York, 1968; http://www.abebooks.com/book-search/title/kineticsmechanism-crystallization-fluid-phase-condensation-evaporation-liquids/page-1/

11. Takoo R K, Cryst Res Technol., 1986, 21(1), 145-150; DOI:10.1002/crat.2170210135 
12. Oki Muraza, Idris Bakara, Ternoki Tago, Hiroki Konno, Adam H, Al-Amer, Zain $\mathrm{H}$ and Takao Masuda, Nanosized of Zeolites with One-Dimensional (1D) Pore Systems and Their Applications in Catalytic Cracking: Proceedings $22^{\text {nd }}$ Saudi Japan Annual Symposium Catalysts in Petroleum Refining \& Petrochemicals KFUPM Dhahran, Saudi Arabia Nov. 25-26, 2012.

13. Ling Zhang, Sujanan Xie, Wenjie Xien, Shenghin Liu and Longya Xu, Mater Res Bull., 2011, 46(6), 894-900; DOI:10.1016/j.materresbull.2011.02.018 